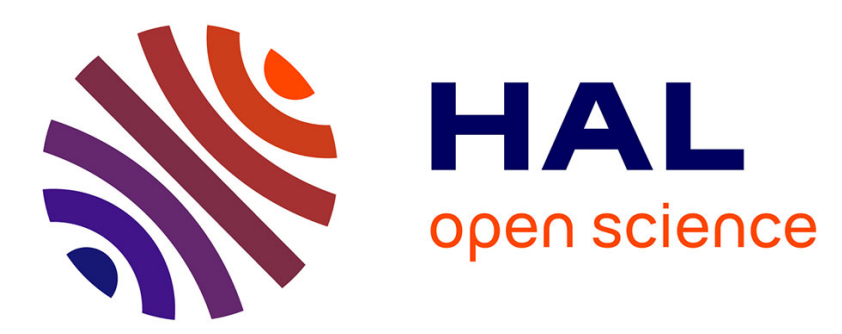

\title{
Adaptive iterative destruction construction heuristic for the firefighters timetabling problem
}

Mohamed-Amine Ouberkouk, Jean-Paul Boufflet, Aziz Moukrim

\section{To cite this version:}

Mohamed-Amine Ouberkouk, Jean-Paul Boufflet, Aziz Moukrim. Adaptive iterative destruction construction heuristic for the firefighters timetabling problem. 22e congrès annuel de la Société Française de Recherche Opérationnelle et d'Aide à la Décision (ROADEF 2021), Apr 2021, Mulhouse, France. hal-03277682

\section{HAL Id: hal-03277682 \\ https://hal.science/hal-03277682}

Submitted on 4 Jul 2021

HAL is a multi-disciplinary open access archive for the deposit and dissemination of scientific research documents, whether they are published or not. The documents may come from teaching and research institutions in France or abroad, or from public or private research centers.
L'archive ouverte pluridisciplinaire HAL, est destinée au dépôt et à la diffusion de documents scientifiques de niveau recherche, publiés ou non, émanant des établissements d'enseignement et de recherche français ou étrangers, des laboratoires publics ou privés. 


\title{
Adaptive iterative destruction construction heuristic for the firefighters timetabling problem
}

\author{
Mohamed-Amine Ouberkouk, Jean-Paul Boufflet, Aziz Mourkim \\ Université de technologie de Compiègne, CNRS, Heudiasyc (Heuristique et Diagnostic des Systèmes \\ Complexes), CS 60319 - 60203 Compiègne Cedex \\ \{mohamed-amine. ouberkouk, jean-paul.boufflet, aziz.moukrim\}@hds.utc.fr
}

Keywords: Timetabling, Firefighters, Adaptive destruction/contruction heuristic

\section{Introduction}

We propose an Integer Linear Programming model and an Adaptive Iterative Destruction Construction Heuristic solution approach to address the real-world firefighters timetabling problem (FFTP) of the INFOCA institution (INcendios FOrestales Comunidad Andaluza) in Andalusia, Spain. The work was initiated as part of the GEO-SAFE project. ${ }^{1}$ The ILP and AIDCH solution approaches are assessed and compared on datasets generated using real-world data of the INFOCA institution.

\section{Problem description}

Timetabling problems $[1,2,3]$ are types of planning problems that involve allocating resources within time slots considering a predefined horizon while respecting precedence, duration, capacity and disjunction constraints. Staff planning aims at building time schedules for staff so that an organization can meet demands for goods or services. For each staff member, the schedule states working and rest days while taking into account work regulation constraints and local regulation constraints of the institution.

The studied problem is to determine the INFOCA's daily schedule within a fixed planning horizon for a number of firefighter crews. Each firefighter is assigned to a crew for a year. These firefighters crews can be assigned to several types of shifts such as helicopter work, night work, work on demand ( 24 hour on call). The planning period is the high-risk period from 1st June to 15th October where wildfires yearly occur (forest fire period).

The objective is to build a schedule for every crew of firefighters while maximizing the overall operating capacity during forest fire periods. We have to respect the minimum demands for each shift, the regulatory constraints imposed by the institution (hard constraints) as well as constraints of good practice in order to make the schedules adequate to the preferences of the institution (soft constraints).

The constraints of good practice relate to the grouping of assignments of same shifts whitin consecutive days, the allocation of compensations after rest days while maximizing of the number of operational crews a day and respecting fairness.

\section{Solution method}

We propose an Integer Linear Programming (ILP) formulation together with an Adaptive Iterative Destruction/Construction Heuristic (AIDCH). The ILP is designed for modeling purposes

\footnotetext{
${ }^{1}$ https://geosafe.lessonsonfire.eu/
} 
and with the aim of giving lower bounds useful for the tuning analysis of the AIDCH solution approach. The heuristic solution is appropriate to generate solutions of good quality for larger instances of the FFTP.

The AIDCH proposed approach works as follows. We use an adaptive construction procedure to build an initial solution. Then, at each iteration, a part of the solution is destroyed by removing at random a number $d$ of crews bounded by $D_{\max }$. Therefore, we define $D_{\max }$ as the degree of diversification. The $D_{\max }$ value is initialized to 3 , next incremented after each non-improving overall iteration. Provided an improvement is found, $D_{\max }$ is reset to 3 with the aim of exploring the neighborhood of the new solution. Finally, we perform an adaptive construction procedure to complete the solution. This process is reiterated and stops when a certain number of consecutive overall iterations have failed to improve the quality of the solution. The final result is the best solution found over all iterations.

The main component of the AIDCH method is the adaptive construction heuristic based on a Best Insertion Algorithm (BIA). Given a partial solution $S$ with the $d$ crews being removed, we attempt to insert one crew at a time. At each iteration, all feasible insertions respecting the hard constraints are first assessed then scored according to a Best Insertion Criterion (BIC). The best insertion is then performed. This process is iterated until all $d$ crews are inserted.

We implemented the proposed solution approaches using CPLEX solver and $\mathrm{C}++$. We tested the proposed ILP and AIDCH with four datasets with different numbers of crews. These datasets where automatically generated using an instance generator based on the real data we collected.

The ILP was able to solve all the instances of the 3 first datasets to optimality and failed to find a solution in the allocated time for the instances of the 4 th dataset (70 crews for each instance of this dataset). The AIDCH method was able to find the optimal solution for $91 \%$ of the instances for which the best solution is known and provided schedules with a better quality than the INFOCA's actual schedules in term of operational capacity, fairness and shift grouping.

\section{Conclusions and perspectives}

We proposed in this work an adaptative iterative destruction construction heuristic (AIDCH) to solve the FFTP. The proposed method is effective and gives good results over the majority of instances. We aim to improve the proposed method to shorten the computational time and to find better solutions for the largest dataset.

\section{Acknowledgments}

This work was initiated as part of the GEO-SAFE project. The GEO-SAFE project has received funding from the European Union's Horizon 2020 research and innovation programme under the Marie Skłodowska-Curie RISE grant agreement No 691161.

\section{References}

[1] Sumer C Aggarwal. A focussed review of scheduling in services. European Journal of Operational Research, 9(2):114-121, 1982.

[2] Andreas T Ernst, Houyuan Jiang, Mohan Krishnamoorthy, and David Sier. Staff scheduling and rostering: A review of applications, methods and models. European journal of operational research, 153(1):3-27, 2004.

[3] James M Tien and Angelica Kamiyama. On manpower scheduling algorithms. SIAM review, 24(3):275-287, 1982. 